\title{
MODELOS DE DECISIONES EN EL MANEJO DE LA COBERTURA ARBÓREA EN FINCAS GANADERAS DE NARIÑO
}

\section{DECISION MODELSIN THE MANAGEMENT OF TREE COVER ATCATTLE FARMS OF NARIÑO}

\author{
Diego Andrés Muñoz G. ${ }^{\text {; j Jorge Fernando Navia E. }{ }^{2} \text {; Beto Moreno }}{ }^{3}$
}

Fecha de recepción: Mayo 05 de 2014 Fecha de aceptación: Noviembre 05 de 2014

\begin{abstract}
RESUMEN
Las decisiones de los agricultores en sus fincas, influyen directa o indirectamente sobre la cobertura arbórea que afectan su estructura, densidad y composición. El presente estudio se desarrolló en los municipios de Guachucal y Cumbal, departamento de Nariño, Colombia con el propósito de identificar los criterios y decisiones claves que toman los agricultores, en el manejo de la cobertura arbórea en fincas ganaderas productoras de leche. Las decisiones, fueron modeladas y simuladas en el programa Netica 2.6. Con las respuestas obtenidas se diseñaron modelos generales de decisión, donde se obtuvo cuatro eventos principales y de mayor influencia en el manejo de la cobertura arbórea, 1) evento poda, 2) evento control de maleza, 3) evento siembra de árboles y 4) evento aprovechamiento de árboles. Las frecuencias, permitieron estimar la probabilidad de cada decisión e influencia de las variables con respecto a los eventos para su modelación y simulación. Además, para profundizar sobre el proceso de toma de decisiones se plantearon escenarios relacionados con las condiciones agroecológicas de la finca, el manejo de la unidad productiva y el entorno en el que opera la finca. Así mismo se analizaron las principales limitantes para el manejo y establecimiento de la cobertura arbórea. El evento de mayor importancia para el manejo de la cobertura arbórea es la poda, debido a su valor en la obtención de leña como combustible, este factor influye en la zona para que las cobertura arbóreas se incrementen como cercas vivas.
\end{abstract}

Palabras clave: Modelación y simulación, sistemas silvopastoriles, sistemas Agroforestales.

1 Profesor Asistente, M.Sc. Universidad de Nariño. Pasto, Colombia. dmunoz@udenar.edu.co

2 Profesor asociado, Ph.D. Universidad de Nariño. Pasto, Colombia, jornavia@yahoo.com

3 Investigador CORPOICA, Ingeniero Agroforestal. Colombia. Universidad de Nariño. 


\begin{abstract}
Decision-making by farmers of the activities conducted at their farms has a direct or indirect influence on tree cover, affecting its structure, density, and composition. This study was conducted at the municipalities of Guachucal and Cumbal, in the department of Nariño, Colombia, with the aim of identifying the criteria and key decisions made by farmers in the management of tree cover in milk-producing cattle farms. The decisions were modeled and simulated in the program Netica 2.6. General decision models were designed from the obtained responses, which yielded four major and most influential events in the management of tree cover: 1) pruning event, 2) weed control event, 3) tree planting event, and 4) tree use event. The frequencies allowed us to estimate the probability of each decision and the influence of variables regarding the events for its subsequent modeling and simulation. In addition, in order to further study the process of decision-making, scenarios relating to agro-ecological conditions of the farm, management of the productive unit, and the environment in which the farm operates were proposed. Furthermore, the main constraints to the management and establishment of tree cover were analyzed. The most important event in the management of tree cover is pruning, given its value in obtaining firewood for fuel, and this factor influences the increase of tree cover as living fences in the zone.
\end{abstract}

Keywords: Modeling and simulation, silvopastoral systems, agroforestry systems.

\section{INTRODUCCIÓN}

La agricultura y la ganadería, se enfrentan al gran desafío de cubrir las necesidades de una población mundial en crecimiento acelerado, y hacerlo de manera sostenible, teniendo en cuenta el manejo del medio ambiente. Esta perspectiva, obliga a conocer y aplicarcuantiosas innovaciones tecnológicas y avances en la racionalización del manejo en fincas (Grupo Editorial Océano, 2000).

En Colombia, por ejemplo, según el Departamento Administrativo Nacional de Estadísticas DANE (2012), el sector pecuario ocupa el 77,5\% de superficie del territorio nacional, con una población de 24.8 millones de cabezas, siendo la tercera en Latinoamérica después de Brasil y Argentina; y participa con el 1,6\%, el 20\% y el $53 \%$ sobre el crecimiento nacional, el sector agropecuario y el sector pecuario, respectivamente; $y$ genera de acuerdo con la Federación Colombiana de Ganaderos (FEDEGAN, 2012), aproximadamente 950000 empleos directos.
En el departamento de Nariño, el sector pecuario ocupa el cuarto renglón de producción, con cerca de 322,709 cabezas de ganado reportadas en el año 2011 (DANE, 2012). El 33,8\% corresponde a la ganadería lechera, con niveles tecnológicos del más avanzado (razas seleccionadas, manejo de praderas, asesoría técnica, inseminación artificial), al más bajo (razas criollas, mínimo manejo de praderas, deficiente asistencia técnica, etc.). La producción total de leche es de 782,694 litros/día aproximadamente, de los cuales el $50 \%$ son industrializados por empresas procesadoras regionales, el 35\% se comercializa fuera del departamento y el $15 \%$ se destina al consumo interno (DANE, 2012).

En los municipios de Cumbal y Guachucal (Nariño), el principal sistema de producción predominante es la ganadería especializada en producción de leche, donde el $70 \%$ de las familias se dedican a esta actividad, representando un aporte fundamental a la generación de ingresos y a la actividad agroindustrial de la región (Esquema de Ordenamiento Territorial municipio 
de Cumbal, 2002). Por eso es conveniente tratar de explicar y predecir las decisiones que toman los productores ganaderos sobre el manejo de la finca en ámbitos diversos. En este sentido, la toma de decisión consiste en la elaboración de una serie de constructos teóricos y articulaciones lógicas que pretenden explicar y predecir el comportamiento de los agentes decisores reales (Romero, 1993; Barrios, 1998). Identificar estas decisiones puede ser importante para ser tenidas en cuenta en procesos de transferencia de tecnologías agroforestales y silvopastoriles. Estudios, han demostrado que la presencia de árboles incrementa la rentabilidad de la finca, pues ofrecen algunos beneficios económicos adicionales como postes madera y leña (Casasola, 2000). De igual manera, otros estudios han demostrado la importancia de la cobertura arbórea en fincas ganaderas para la conservación de la biodiversidad (CIPAV, 2001).

Las decisiones de los agricultores, sobre las actividades a llevar a cabo en sus fincas influyen directa o indirectamente sobre la cobertura arbórea, afectando su estructura, densidad y composición. Así mismo, Deffontaines et al. (1995), señalan que las condiciones físicas del ambiente inciden en la toma de decisiones de los finqueros respecto a la adaptación de los tipos de usos del suelo y actividades técnicas dentro de las fincas.

Los modelos generales de toma de decisión se pueden elaborar y simular en diversos programas computarizados, uno de ellos es Netica (Norsys, 1998), el cual genera una red compuesta de todos los factores o variables (llamados nodos naturales) que influyen en la toma de la decisión que se desea investigar. Cada nodo presenta divisiones llamadas estados; por ejemplo, el nodo "disponibilidad de capital" presentó los estados alto y bajo.
Los valores de cada estado están dados en probabilidades ( 0 a $100 \%)$, las cuales provienen de las frecuencias relativas de las respuestas emitidas por los productores. Netica puede utilizarlos diagramasdeinfluencia paraencontrar las decisiones óptimas que maximicen los valores esperados de las variables especificadas.

Este trabajo tuvo como objetivos identificar las principales actividades que afectan la cobertura arbórea en las fincas ganaderas de los municipios de Cumbal y Guachucal; así también elaborar modelos de toma de decisiones de los ganaderos sobre los eventos de mayor relevancia que afectan la cobertura arbórea, y efectuar simulaciones de cambios de cobertura arbórea en diferentes escenarios alternativos.

\section{METODOLÓGIA}

\section{Características generales de la zona}

Los municipios de Cumbal y Guachucal se ubican al sur occidente del departamento de Nariño, se consideran como una región de piso térmico frío a una altura de $3125 \mathrm{msnm}$, temperatura promedio de $10{ }^{\circ} \mathrm{C}$, precipitación entre $1000 \mathrm{y}$ $2000 \mathrm{~mm}$ /año, suman una extensión de 847 Km2, se localizan entre las coordenadas geográficas: $\mathrm{N}$ $0^{\circ}, 96^{\prime \prime}$; y W 77, 49" (Esquema de Ordenamiento Territorial de Guachucal, 2006).

El presente trabajo, se fundamentó en una metodología en la cual la información de toma de decisiones es de tipo descriptivo y probabilístico de ocurrencia de eventos, donde se recolecta mediante informantes claves y se procesa y analiza en el programa Netica 2.6 (Norsys, 1998), para posteriormente obtener un modelo de decisión general para cada uno de los eventos de estudio (poda, control de maleza, siembra 
de árboles y aprovechamiento de árboles). Esta metodología se llevó a cabo con los siguientes procedimientos:

\section{Estratificación}

En el municipio de Cumbal y Guachucal, como en otros de población indígena, se han realizado procesos de organización y recuperación de tierras que quizás modificaron las prácticas y costumbres tradicionales, por lo cual se creería que este factor influye en diferencias de toma de decisiones. De acuerdo a lo anterior, los productores fueron estratificados teniendo en cuenta el área de la finca, debido a que se considera que una finca al tener mayor área, permite al productor interactuar con un sinnúmero de especies arbustivas y leñosas que enriquecen su conocimiento y forma de proceder para tomar una decisión dentro de su finca, lo que posiblemente no suceda en fincas de áreas relativamente pequeñas. De ésta manera se definieron tres estratos: estrato I ( $<$ de 3 ha), estrato II ( 3 a 6 has) y estrato III (>de 6 ha).

\section{Selección de fincas e informantes claves}

La selección de fincas en cada estrato, se realizó con base en los siguientes criterios: que la ganadería fuese la actividad más importante en el uso de la tierra, accesibilidad a la finca y consentimiento del propietario para brindar información durante 8 meses con visitas mensuales. La elección de los entrevistados, se realizó mediante la metodología del muestreo dirigido propuesto por Glaser y Strauss (1967); es decir se eligieron productores que estén dispuestos a colaborar, sean comunicativos y abiertos a compartir sus conocimientos y narrar sus labores dentro de la finca. En total se seleccionaron 15 informantes claves (cinco por estrato).

\section{Recolección de la información}

Las fincas seleccionadas se visitaron durante ocho meses, con una frecuencia de una vez por mes; se recolectó información sobre las decisiones tomadas por los productores que afectan la cobertura arbórea. La información se obtuvo por medio de una encuesta semi-estructurada, donde se tuvo en cuenta aspectos tales como: los productos generados por la finca, el manejo de pasturas (control de malezas, fertilización, prácticas para retener árboles de regeneración natural o siembra), manejo de cercas vivas (podas, siembras y aprovechamiento de individuos), actividades en bosques, bosques riparios, entre otros (raleos, aprovechamiento, eliminación y protección de individuos) y actividades en áreas de cultivos (siembra de árboles, eliminación de árboles y rotación de cultivos a pasturas). Además de los datos brindados por el propietario o administrador, se recorrió la finca para verificar y ajustar la información.

Al finalizar las primeras dos visitas mensuales a las fincas, se replantearon las encuestas semiestructuradas, y se identificó que las actividades más importantes que afectan la cobertura arbórea fueron: la poda y el control de malezas, seguido con la siembra y el aprovechamiento de árboles. Especialmente, se profundizo en encontrar las variables que actúan sobre la decisión de realizar cada uno de estos eventos. En los siguientes seis meses del estudio, se realizaron las visitas normalmente pero con las modificaciones al formato original y así se logró terminar la recolección de la información sobre toma decisiones claves que influyen en el componente arbóreo.

\section{Generación de diagramas de decisión}

Con la información que se obtuvo por medio de las encuestas a los agricultores y las observaciones de campo, se diseñaron modelos generales 
de decisión para cada uno de los eventos. Con el respectivo análisis de frecuencia de las respuestas obtenidas se determinó la probabilidad de cada uno de los nodos principales y secundarios según los casos considerados. Cada decisión o evento estuvo compuesto de uno o varios nodos principales o primarios y secundarios; los principales constituyeron la decisión de realizar el evento y los secundarios fueron los factores o variables que llegaron a afectar el nodo principal.

\section{Simulación de escenarios}

En el programa Netica 2.6 se procedió a simular escenarios cambiando el valor de la probabilidad del estado de un factor o de varios factores, y así se consiguió detallar los factores de mayor importancia en la toma de decisiones de los productores. Este ejercicio implicó el cambio de la probabilidad del estado de un factor a un valor alto (100\%) o al extremo bajo (0\%), así como también se combinaron dos o más factores.

\section{Validación de los modelos}

El objetivo de la validación fue para corroborar la viabilidad de los modelos obtenidos en cada evento (poda, control de maleza, siembra de árboles y aprovechamiento de árboles), para esto, se llevó a cabo la elaboración y ejecución de 10 encuestas semi-estructuradas, con el respectivo dialogo y discusión de los modelos con los agricultores.

\section{RESULTADOS Y DISCUSIÓN}

Se identificaron cuatro eventos que influyeron en el manejo de la cobertura arbórea en fincas ganaderas de los municipios de Cumbal y Guachucal. Los cuatro eventos fueron: 1) control de maleza, 2) aprovechamiento de árboles, 3) siembra de árboles y 4) poda de árboles. Cada uno de ellos tiene un impacto distinto sobre la cobertura arbórea.

\section{Evento poda de cobertura arbórea}

La poda es el evento más significativo y de mayor frecuencia realizado por los productores ganaderos en Guachucal y Cumbal. La poda se realiza con el objetivo de satisfacer las necesidades de productos para el autoconsumo en la finca. Los principales subproductos extraídos por los productores fueron leña, poste, madera y forraje (muy pocas veces). Para tomar la decisión de podar los árboles de la finca, los productores tienen en cuenta la necesidad de hacer uso del producto de la poda, ya sea para leña cuando la provisión de su finca escasea, o cuando necesitan reparar las cercas, o forraje para alimentar al ganado esporádicamente. Los árboles predominantes que manejan en dichas zonas son: pino Pinus patula Schiede ex Schltdl. y Cham, eucalipto Eucaliptus globulus Labill, ciprés Cupresus lusitánica Mill, acacia Acacia melanoxylon R.B, Acacia decurrens Willd., aliso Alnus acuminata (Botina y Taramuel, 2009).

El seguimiento del evento poda, arrojó como resultado el modelo general indicado en la Figura 1, mostrando que esta labor es realizada en su mayoría por mano de obra familiar $(97 \%$ de probabilidad). Turcios (2008), señala en el $100 \%$ de los casos, la mano de obra familiar tiene participación en todas las fases del cultivo, desde el cambio de uso del suelo hasta el aprovechamiento en la finca. Este evento (poda), depende directamente de la necesidad de leña de la finca con $70,6 \%$ de influencia. El tipo de poda predominante, es parcial con $61,6 \%$ de probabilidad, Villanueva et al. (2004), en un estudio de toma de decisiones encontraron igual tendencia donde mencionan, que la mayoría de las podas realizadas en Peten Guatemala por productores ganaderos son parciales (probabilidad de 49\%). En Guachucal y Cumbal tienen preferencia a podar los árboles jóvenes posiblemente. 


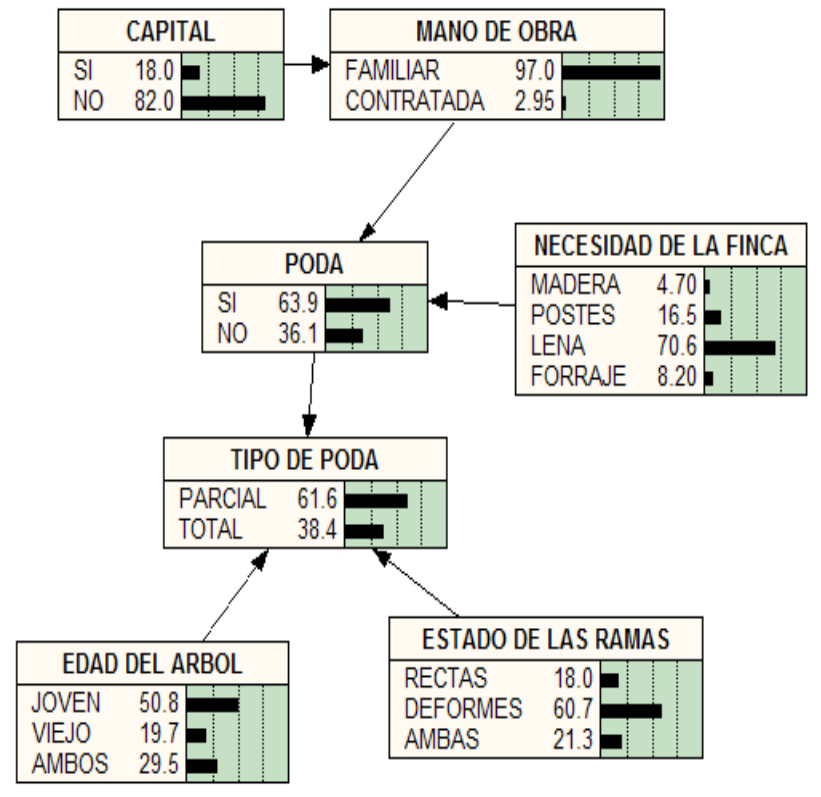

Figura 1. Modelo general en Netica 2.6 de toma de decisiones para el evento poda de las coberturas arbóreas (2012)

Si hacen la poda, existe un $60,7 \%$ de probabilidad de que se poden las ramas torcidas, y un $18 \%$ que elijan ramas rectas. Existe una relación entre disponibilidad de capital y tipo de mano de obra; el capital hace referencia a los recursos asignados para esta labor (poda), lo cual indica que los ganaderos de Guachucal y Cumbal no disponen de capital para mano de obra contratada $(2,95 \%)$; esto no implica que la poda no se realiza, debido a que esta actividad es considerada como labores domésticas para cubrir principales necesidades de la finca como leña principalmente. De igual manera, la edad del árbol y el estado de las ramas son variables que influyen también en el tipo de poda y la mano de obra y la necesidad de la finca son factores que determinan la probabilidad de que se efectúen o nó las podas. Se determino un $63,9 \%$ de probabilidad de realizar la poda; al respecto, Villanueva et al (2004), en un estudio de toma de decisión sobre la cobertura arbórea en Cañas, Costa Rica encontró igual tendencia en la poda, con una probabilidad de llevarse a cabo del 65,5\%.

\section{Simulaciones del evento poda de árboles}

La necesidad de la finca y la mano de obra, son las principales variables que determinan la dedición de podar o no realizar la poda. Si la probabilidad de que la necesidad de la finca sea leña, es del 100\% (Fig. 2a), la probabilidad de que el agricultor decida podar, aumenta a 69,9\%. Con una probabilidad de que la mano de obra sea $100 \%$ contratada y la necesidad de la finca sea $100 \%$ para leña (Fig. 2b), la probabilidad de que se lleve a cabo la poda es $67,8 \%$, disminuyó pero no es significativo debido a que la necesidad de leña ejerce una fuerte presión en cuanto a la decisión de podar o no, aunque la mano de obra sea contratada, esto implicaría que el agricultor si no cuenta con mano de obra familiar debe disponer de capital para realizar esta labor siempre y cuando la necesidad de leña sea del 100\%. Sin embargo, si la necesidad la finca fuera madera ( $100 \%$ de probabilidad) y la mano de obra siguiera siendo 100\% contratada (Fig. 3), la probabilidad de que se realice la poda es $32,2 \%$ y redujo significativamente, por lo que la necesidad de madera es esporádica y tiene poca demanda para los productores ganaderos de Guachucal y Cumbal.

\section{Evento control de malezas}

El control de malezas en potreros, representa una actividad significativa para el manejo de la finca, ya que se realiza con frecuencia por su rápido crecimiento, especialmente en épocas de lluvia, que afecta directamente la calidad de los pastos que es el principal suministro alimenticio del ganado. Por otro lado, la regeneración natural de especies arbóreas y arbustivas solo es permitida en cercas vivas con una previa selección. 


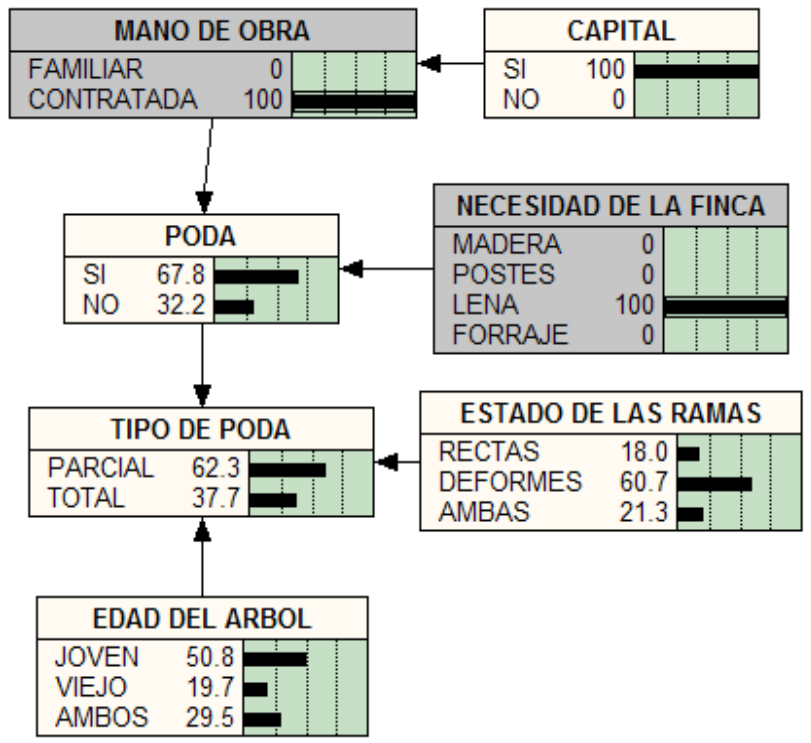

a)

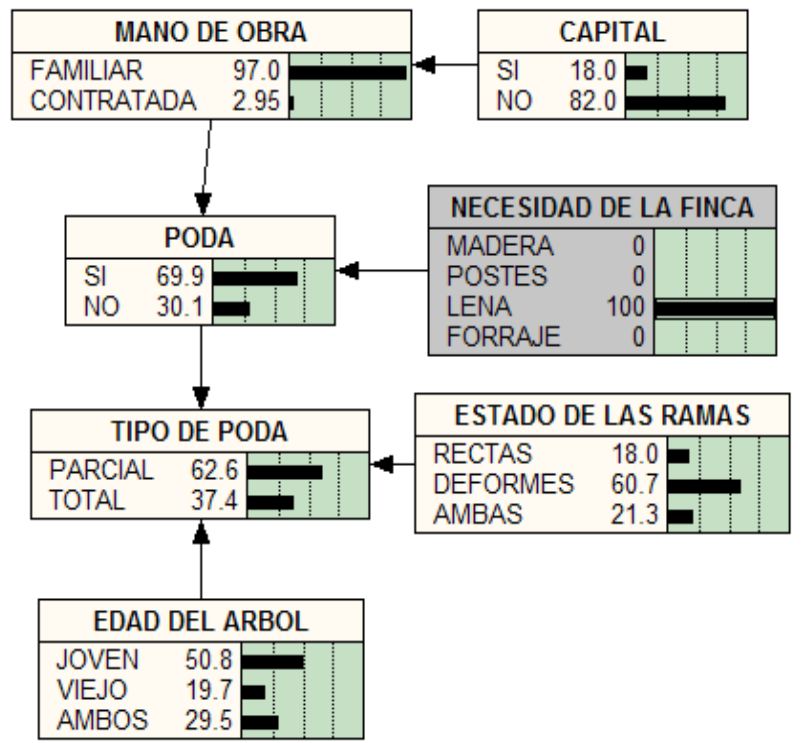

b)

Figura 2. Simulación de necesidad de la finca (leña 100\%) y mano de obra utilizada para la poda (contratada $100 \%$ )

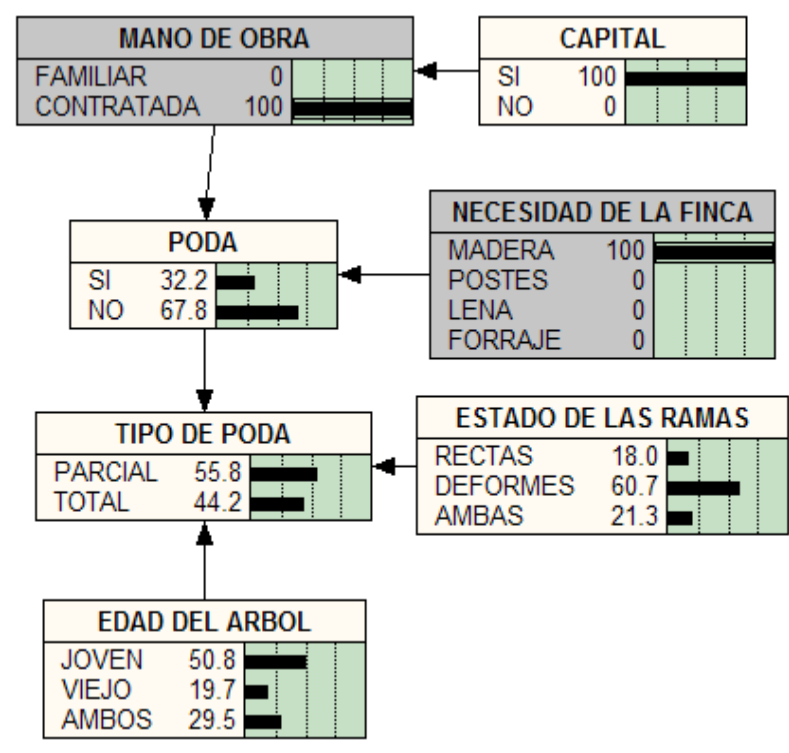

Figura 3. Simulación de necesidad de la finca (madera 100\%) y mano de obra utilizada para la poda (contratada $100 \%$ )

\section{Decisiones y factores que influyen en el control de malezas}

En el control de malezas, se identificaron tres decisiones importantes: la densidad de maleza, método de control y la decisión de controlar o no controlar la maleza.
En el modelo general (Fig. 4), se identificó que las variables determinantes para decidir si se realiza la labor de control de maleza son: tipo de mano de obra, disponibilidad de capital y densidad de la maleza. Cuando se hace el control de malezas, el método realizado es el manual; al respecto, en un estudio similar hecho por Gómez et al. (2004), en Belén, Rivas, Nicaragua, encontraron que todos los productores ganaderos utilizan el control manual, pero en la época lluviosa algunos productores $(n=5)$ combinan el control manual de malezas con el control químico. Los resultados de la validación, indicaron que los productores realizan el control manual por facilidad y economía, argumentando poca dominancia de maleza por el pastoreo del ganado, por eso creen conveniente y más fácil el control manual. La probabilidad de que se realice el control de maleza según los resultados es de 77,6\%, cuando existe una probabilidad del $48 \%$ de que la densidad de la maleza sea alta y que exista suficiente disponibilidad de mano de obra familiar (92,3\%). Villanueva et al. (2004) en un estudio de toma de decisiones en Cañas, Costa Rica, reflejan 
igual tendencia, hubo una probabilidad del 95\% de que se llevara a cabo el control de malezas. La mano de obra se relaciona con la disponibilidad de dinero, cuando es alta tenderá a mayor disponibilidad de mano de obra contratada, pero la costumbre de la población es utilizar mano de obra familiar, por lo tanto, la probabilidad de que realice control de malezas disminuirá.

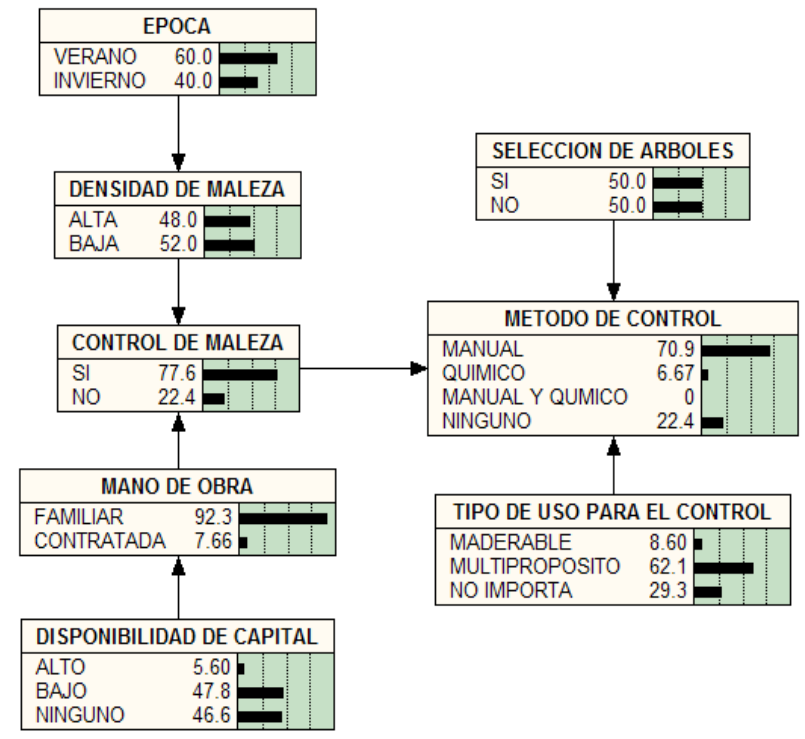

Figura 4. Modelo general en Netica 2.6 de toma de decisiones para el evento control de malezas

Se determinó que si la época es invierno o verano, son causas para que la densidad de maleza aumente o disminuya; en verano, existe una probabilidad del $52 \%$ de que la densidad de maleza es de tendencia baja. Gómez et al. (2004), mencionan que las malezas crecen más lentamente en verano y pueden ser fácilmente controladas con el control manual, en cambio en la estación lluviosa, algunos productores optan por controlar las malezas con químicos, porque tienen una germinación más rápida y un mayor crecimiento que en la época seca.

\section{Simulación del modelo control de malezas}

Simulando una disponibilidad alta de dinero (100\%), se presenta una probabilidad del $60 \%$ de que se contrate mano de obra; esto hace que la probabilidad de efectuar control de malezas sea del 50,4\% (Fig. 5). Esto se debe, a que con disponibilidad de dinero algunos productores optarían por contratar mano de obra, pero sin dejar de utilizar la mano de obra familiar; sin embargo, la labor de control de malezas se vería afectada por que se realizaría en menor proporción, ya que para los agricultores de Guachucal y Cumbal el control de malezas en potreros, demanda poca mano de obra y prefieren utilizar mano de obra familiar. En los resultados de la validación los agricultores resaltan "no acostumbramos a disponer de mano de obra contratada para labores que necesitan de poco personal". Villanueva et al. (2004) en un estudio de toma de decisiones resalta que los finqueros de Cañas, Costa Rica catalogan el control de malezas como imprescindible, ya que su ausencia repercute en la persistencia de la pastura (especialmente en pastos introducidos) y consecuentemente, en la productividad animal.

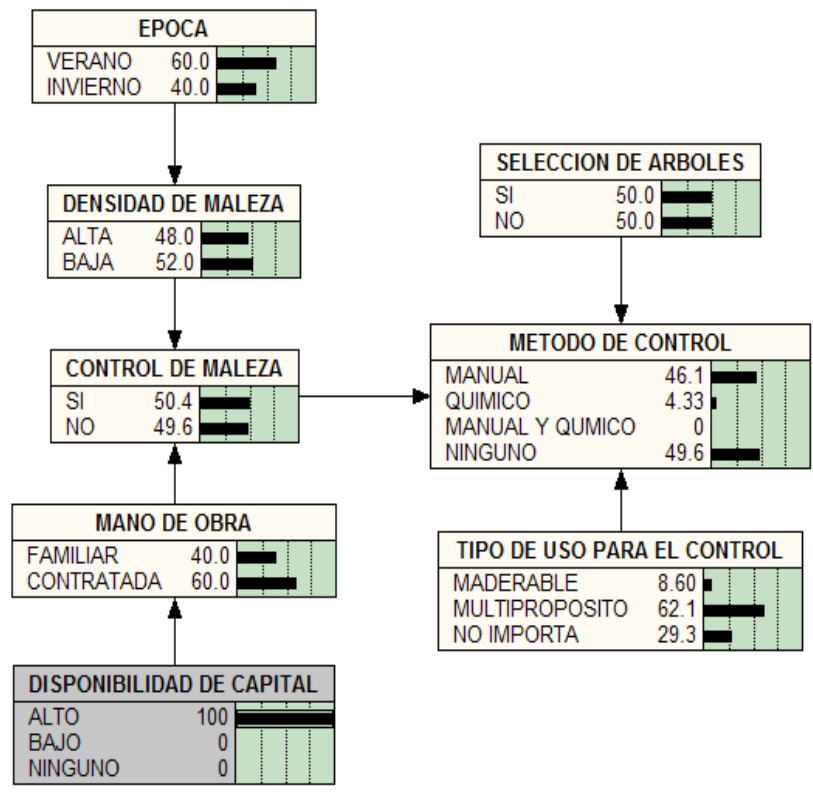

Figura 5. Simulación del modelo de control de malezas en Netica 2.6 para disponibilidad de capital 
Simulando probabilidades del $100 \%$ para la densidad de maleza alta (Fig. 6), se presenta una posibilidad del $80 \%$ de que se realice el control de malezas; esto indica que la densidad de malezas es un factor determinante a la hora de tomar la decisión de realizar el control; la frecuencia de realizar el control de malezas se lo atribuyen a las temporadas de lluvia que es donde más se efectúa el control. Turcios (2008), en el estudio de toma de decisiones señala, que los productores de Peten, Guatemala deben combatir las malezas principalmente en la época lluviosa, sin embargo el $14 \%$ de productores menciona que el control ha sido necesario también en la época seca.

Simulando una probabilidad de época verano 100\% (Fig. 7), el modelo indica una influencia significativa en cuanto a la densidad de malezas, ya que se observó una disminución a 33,3\% de probabilidad y con la simulación de una probabilidad de época invierno 100\% (Fig. 7), hubo un aumento en la densidad de malezas con la probabilidad del $70 \%$, ocasionando un aumento en el control de malezas $(78,6 \%$ de posibilidad). En la validación del evento control de malezas, se determinó que los productores

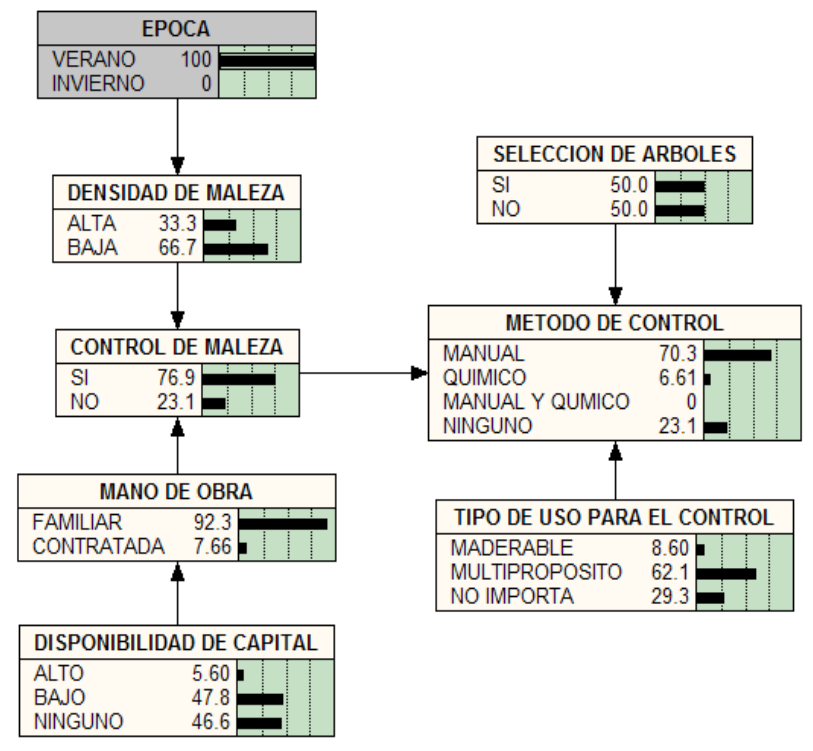

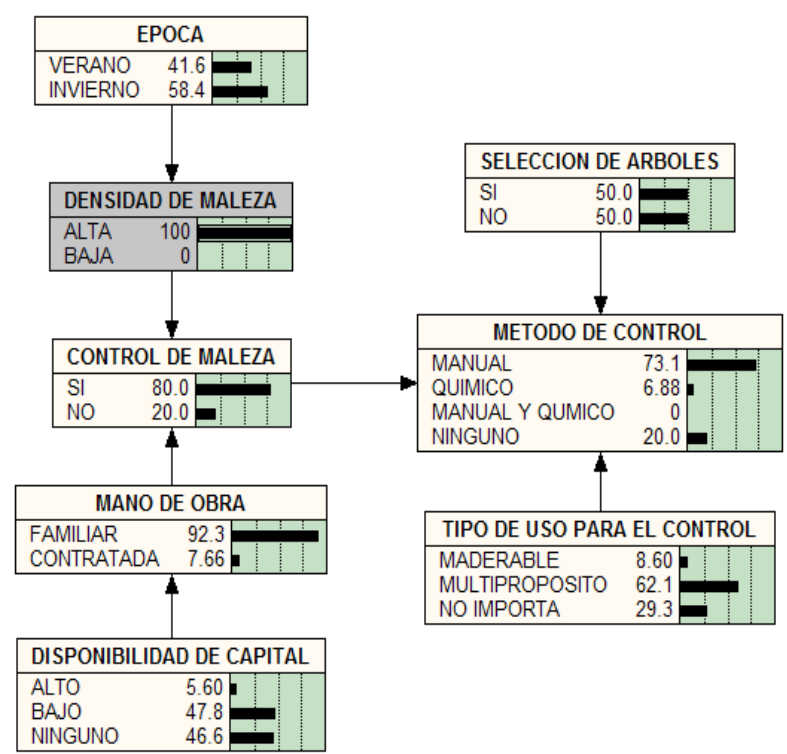

Figura 6. Simulación del modelo de control de malezas en Netica 2.6 para la densidad de maleza alta $(100 \%)$

ganaderos aumentan la frecuencia del control de malezas dependiendo de la época (invierno o verano). Villanueva et al. (2004), en el estudio de toma de decisiones, encontró que el método manual se realiza durante todo el año, pero la mayoría de las fincas prefiere llevarlo a cabo durante la época lluviosa, porque comprende los meses de mayor crecimiento de malezas.

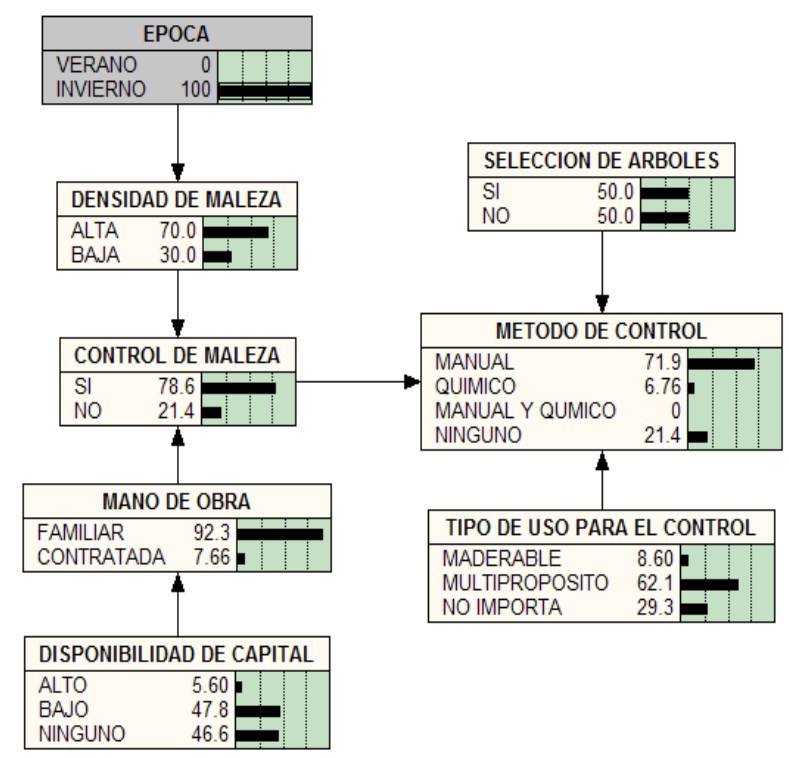

Figura 7. Simulación del modelo de control de malezas en Netica 2.6, época verano e invierno (100\%) 
como, pino Pinus patula Schiede ex Schltdl. \& Cham, eucalipto Eucaliptus globulus Labill, ciprés Cupresus lusitánica Mill son considerados árboles no aptos para tener en la finca (secan la tierra) dicen los productores ganaderos entrevistados, esto confirmaloreportado por Botina y Taramuel (2009), en el estudio de caracterización biofísica en el municipio de Cumbal, Nariño, presentan que son especies que generan efectos negativos como secamiento y endurecimiento del suelo reduciendo su potencial productivo. Por lo tanto, los productores, están en proceso de renovarlos y en otras ocasiones los aprovechan por ser límites de finca.

\section{Decisiones y factores que influyen en el aprovechamiento de árboles}

La decisión de aprovechar árboles en las fincas ganaderas, se toma principalmente cuando hay necesidad de leña, que es el insumo proveniente de los árboles que más demanda tiene, además, de la necesidad de postes cuando se requiere cambiar o renovar cercas muertas; la necesidad de madera se requiere muy pocas veces y muy poco la utilizan. Se encontró que en la zona tienen preferencia por maderas externas al lugar, o no se consiguen el la zona. Según Botina y Taramuel (2009) en Cumbal, los finqueros identifican atributos que hacen de una especie arbórea apropiada como fuente de energía; resaltan principalmente la duración de la braza y la cantidad de cenizas que producen, conocen que el Pinus patula Schiede ex Schltdl. \& Cham, Eucaliptus globulus Labill, Cupresus lusitánica Mill, Acacia melanoxylon R.B, Acacia decurrens Willd., Alnus acuminata producen baja cantidad de braza y alta ceniza, pero sin embargo son las más utilizadas como leña debido a su alta disponibilidad en la zona.

Los productores ganaderos consideran toda labor que tenga que ver con la cobertura arbórea como secundaria para actividades de explota- ción, y más bien es considerada como recursos para el sostenimiento del hogar que cubren principalmente las necesidades de la finca, por ese motivo y en mayor parte todo lo relacionado con la siembra hasta el aprovechamiento es realizado por mano de obra familiar. León (2006), en un estudio de conocimiento local y razonamiento agroecológico para la toma de decisiones, argumenta que existe una alta participación de la mano de obra familiar en las labores de fincas ganaderas pequeñas y medianas en el Peten, Guatemala. Sin embargo, cuando hay necesidad de leña, el agricultor puede disponer de mano de obra contratada según considere.

Se determinó una probabilidad del $58,1 \%$ de relación al aprovechamiento de árboles si se cumple las siguientes condiciones probabilísticas (Fig. 8): necesidad de leña $65 \%$ y necesidad de dinero $55 \%$. La necesidad de dinero esta manifestada como algo que siempre faltará y por lo tanto no ejerce mucha presión en cuanto a la decisión de aprovechar, mas bien cuando la necesidad de dinero es alta proceden a aprovechar los productos de su explotación principal (leche). De igual manera, Lasso et al. (2009), señalan que el sistema de producción ganadero de leche ocupa el $95 \%$ del área total de los potreros en el municipio de Cumbal. El lugar de aprovechamiento son las cercas vivas que es el sistema predominante de la zona. Coral et al. (2009), señalan que para los productores de Pupiales la idea de mantener una cobertura arbórea dentro del predio es cada vez mas difícil de aceptar, pues afirman que si lo hace pierde terreno apto para la agricultura. De igual manera, Cajas et al. (2009), en un estudio de caracterización biofísica confirman que en las fincas ganaderas de Guachuca,l el 100\% presentan cercas vivas. Con $35 \%$ de suceso, la necesidad de postes, juega un papel importante al momento de decidir o no el aprovechamiento de árboles. 


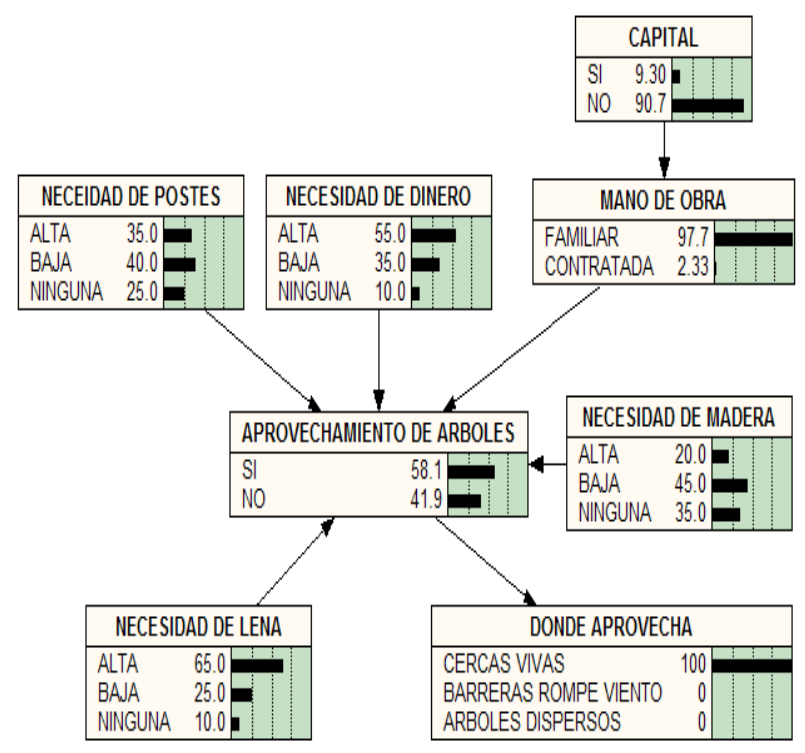

Figura 8. Modelo general en Netica 2.6 de toma de decisiones para el evento aprovechamiento de árboles

\section{Simulación del modelo aprovechamiento de árboles}

Simulando un $100 \%$ de probabilidad (Fig. 9) de que se haga aprovechamiento en la zona, ésta decisión está directamente influenciada por la variable necesidad de leña, ya que aumentó considerablemente a 80,1\% (alta), sufriendo un aumento de más del 15\%, cuando las demás

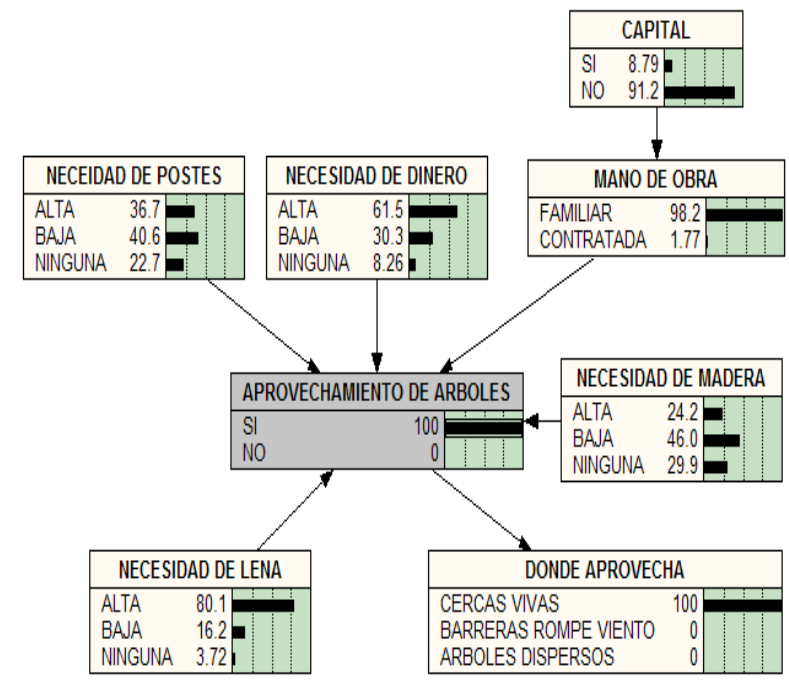

Figura 9. Simulación del modelo aprovechamiento de árboles en Netica 2.6 para aprovechamiento de árboles $(100 \%)$ aumentaron de 1 - 5\%, esto da a entender que la necesidad de leña es el factor que más incide, en que la cobertura arbórea disminuya. Según Cajas et al. (2009), los principales causantes de la disminución de la cobertura arbórea en las fincas ganaderas de Guachucal, son los usos de leñapostes-madera con el 57\% de disminución.

Simulando un $100 \%$ de probabilidad de que la necesidad de leña y madera sea alta (Fig. 10), se determinó que la probabilidad de realizar el aprovechamiento de árboles es $84 \%$. Con la simulación de las variables necesidad de leña y necesidad de postes con el $100 \%$ de probabilidad que sea alta (Fig. 10), el aprovechamiento de árboles se realiza con el 73,6\%. Sin embargo simulando las variables, necesidad de leña y necesidad de dinero con el $100 \%$ de probabilidad alta (Fig. 11), el aprovechamiento de los árboles se realizará con $77,6 \%$ de probabilidad. Las variables necesidad de leña y necesidad de madera, son los dos factores de mayor influencia para el evento aprovechamiento de árboles dado, que los diferentes escenarios simulados representan la mayor probabilidad de que se efectúe el aprovechamiento de árboles. Esto confirma lo dicho por Coral et al. (2009), quienes sostienen que una de las principales causa de la disminución de la cobertura arbórea en fincas ganaderas de Pupiales es el consumo de leña. Cajas et al. (2009), en un estudio de caracterización biofísica en Guachucal manifiesta que el 47\% corresponde al uso de postes y leña.

La validación del modelo de aprovechamiento de árboles, concuerda con las simulaciónes obtenida, donde los agricultores aseguran que la principal razón del aprovechamiento es para leña con el fin de brindarse calor y cocción de los alimentos de las familias por ahorro de dinero y por que los alimentos saben mejor; también cocinan alimentos para sus animales por facilidad (tamaño de la olla) y rapidez. 

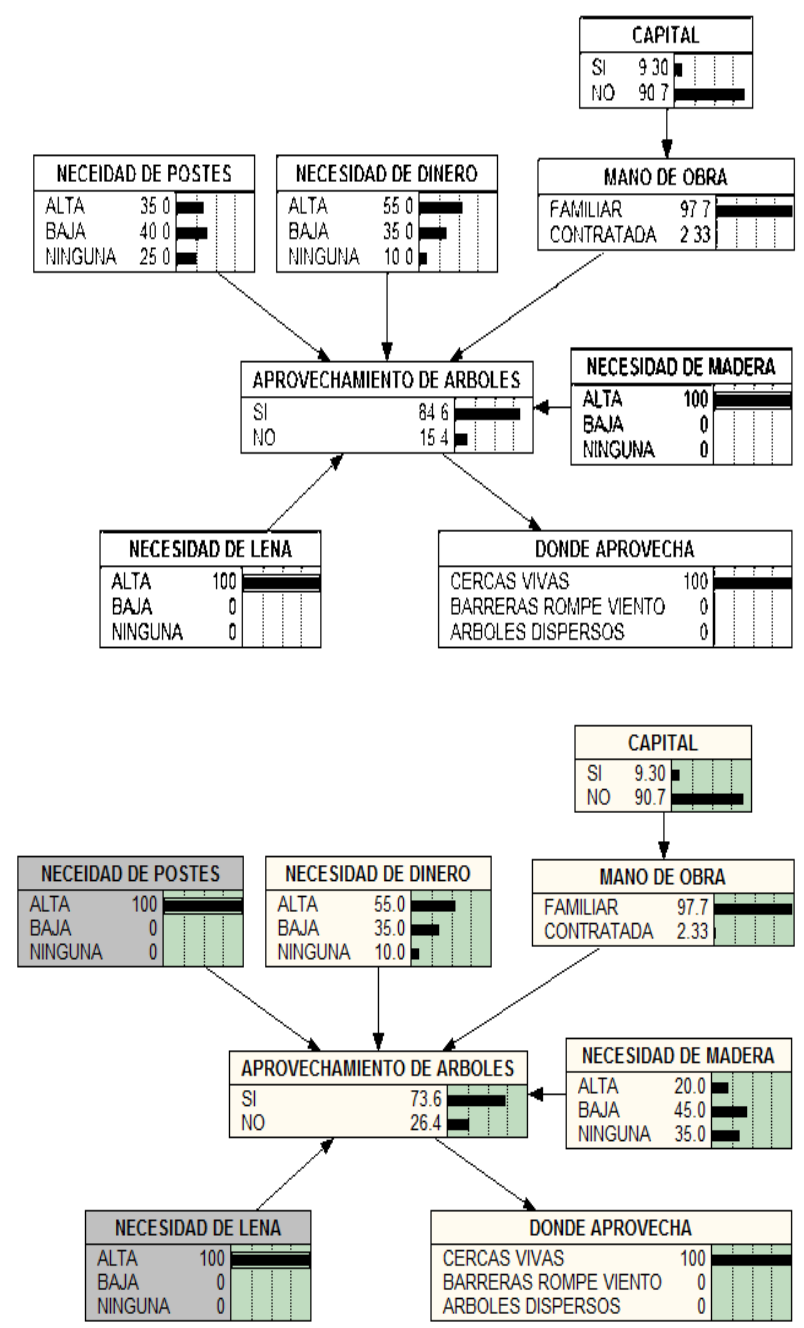

Figura 10. Simulación del evento aprovechamiento de árboles con diferentes necesidades

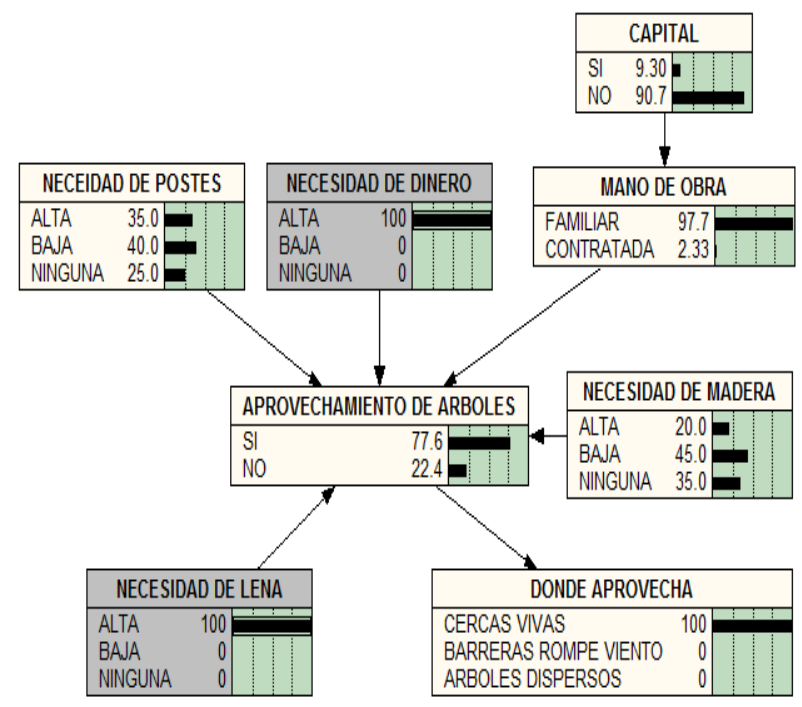

Figura 11. Simulación del evento aprovechamiento de árboles con diferentes necesidades

\section{Evento establecimiento de coberturas arbóreas}

La siembra de la cobertura arbórea, es una actividad que se efectúa muy pocas veces en los municipios de Guachucal y Cumbal, debido a la ganadería de leche extensiva y por el poco conocimiento de sistemas agroforestales que se puedan aplicar en la zona con excepción de cercas vivas. Cajas et al. (2009), afirman que los productores ganaderos de Guachucal aprovechan la cobertura arbórea para leña, postes y madera pero no realizan resiembra de árboles. Gracias a la influencia de algunos proyectos que se desarrollan en la zona se ha logrado cambiar algunos aspectos con respecto a la cobertura arbórea y se han dispuesto a renovar árboles existentes como Eucaliptus globulus Labill, Cupresus lusitánica Mill y Pinus patula Schiede ex Schltdl y Cham, porque son especies consideradas no aptas para la zona y los están remplazando por Acacia melanoxylon R.B, Acacia decurrens Willd, Alnus acuminata, principalmente.

Botina y Taramuel (2009), en un estudio de conocimiento local, encontraron que los ganaderos de Cumbal, atribuyen al componente arbóreo efectos positivos y negativos sobre el suelo, y que dependen del tipo de especie, por ejemplo, Eucaliptus globulus Labill, Cupresus lusitánica Mill y Pinus patula, son especies que generan efectos negativos como resecamiento y endurecimiento del suelo, reduciendo su potencial productivo. Además, se tiene el conocimiento, de que éstas especies influyen en la estructura del suelo, manifestando que adquieren una estructura "polvosa", considerada como un indicio de infertilidad. En cambio, atribuyen efectos positivos a especies como Acacia melanoxylon y decurrens, Alnus acuminata y árboles nativos, ya que perciben que la sombra y el aporte de hojarasca de éstas, mejoran las condiciones de fertilidad del suelo. 
La necesidad de leña, influye directamente en la siembra de nuevos árboles acorde con la demanda de la finca, que como sistema predominante en la zona es la implementación de cercas vivas bien para división de potreros o limites de finca. Coral et al. (2009), en un estudio de conocimiento local en Pupiales encontraron que las praderas se mantienen aisladas del componente arbóreo y está únicamente en arreglos de cercas vivas o linderos de delimitación. Cajas et al. (2009) señalan que los ganaderos de Guachucal afirman que la implementación de las cercas vivas representan varios beneficios como: linderos, límites de los potreros de la finca, producción de leña, madera, postes, además equivalen a menos costos en el establecimiento.

El sistema de cercas vivas ha tomado mayor relevancia económica y ecológica no solo porque su establecimiento significa un ahorro del $54 \%$ con respecto al costo de las cercas convencionales, sino porque constituye una forma de reducir la presión sobre el bosque para la obtención de postes y leña, además que representa una forma de introducir árboles en los potreros (Holman et al., 1992).

\section{Decisiones y factores que influyen en el establecimiento de cobertura arbórea}

El evento siembra de árboles, es una actividad que depende principalmente de la disponibilidad de plántulas, necesidad de siembra y asesoría prestada. El modelo obtenido (Fig. 12) indica que la siembra de árboles se realizó con $34,1 \%$ de probabilidad; con igual tendencia, Villanueva et al. (2004) en el estudio de decisiones claves que influyen sobre la cobertura arbórea en Cañas, Costa Rica, manifiestan que la plantación de postes vivos muestra una probabilidad de ejecución del 35,4\%. La necesidad de siembra con el estado leña $48,9 \%$ de probabilidad y disponibilidad de plantas con el estado alto $68,3 \%$, son los factores más determinantes al momento de tomar la decisión de sembrar árboles. Los agricultores prefieren sembrar en época de lluvia. Turcios (2008), en la evaluación del proceso de decisiones en Petén, Guatemala, encontró que la mitad de los productores adoptadores se inclina hacerlo en época de lluvia, con la mayor tendencia. La asesoría es fundamental para impulsar el establecimiento de árboles pero en general es baja. El mismo autor, argumenta que el alto índice de éxito en la siembra se atribuye al proceso de aprendizaje en que estuvieron participando los productores.

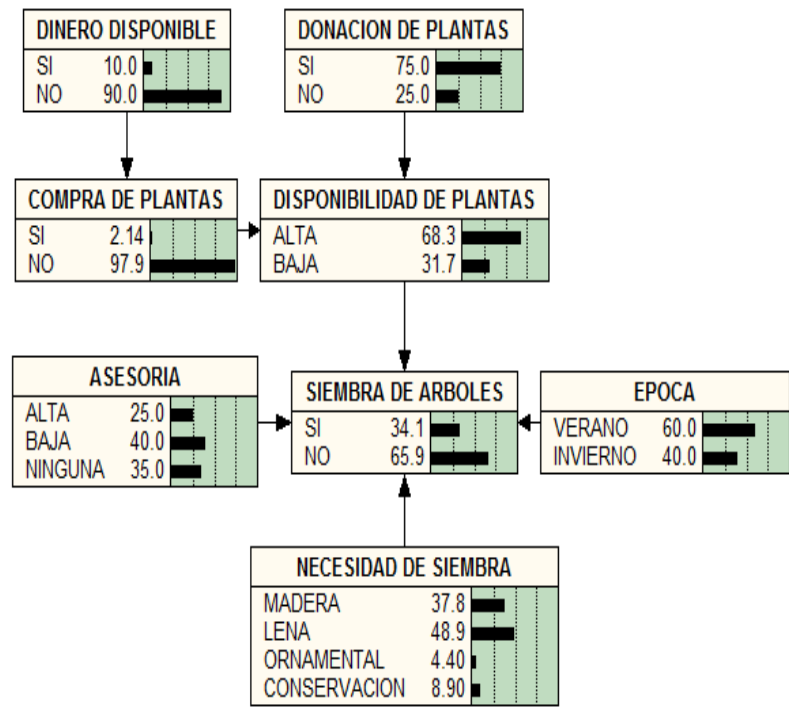

Figura 12. Modelo general en Netica 2.6 de toma de decisiones para el evento siembra de árboles

\section{Simulación del modelo siembra de árboles}

Simulando un $100 \%$ de posibilidad de tomar la decisión de llevar a cabo la siembra (Fig. 13), se determinó que la necesidad de siembra seria la variable determinante en esta decisión con el estado "leña" (59,5\% de probabilidad), seguido de la necesidad de madera $37,9 \%$ de probabilidad); los productores ganaderos se inclinan por sembrar en época de invierno (63,4\% de probabilidad), siempre y cuando la disponibilidad de plantas sea alta $(77,7 \%)$. 


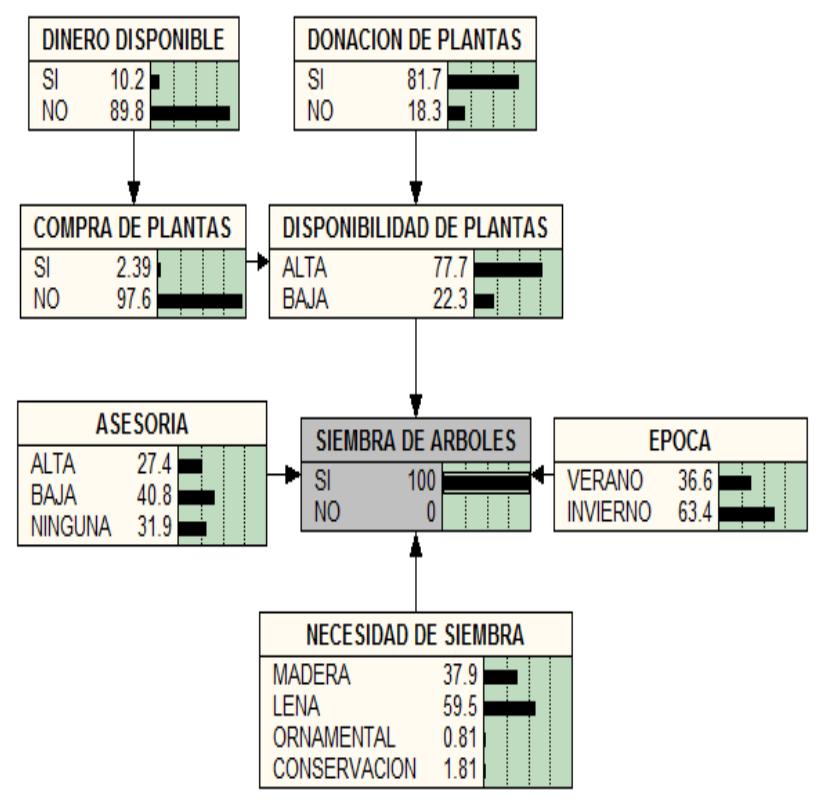

Figura 13. Simulación del evento siembra de árboles con $100 \%$ de probabilidad

Haciendo una simulación con probabilidades del $100 \%$ para las variables necesidad de siembra de madera y época de invierno, las probabilidades de sembrar árboles son del $55,6 \%$ (Fig. 14). Si la época fuese verano con

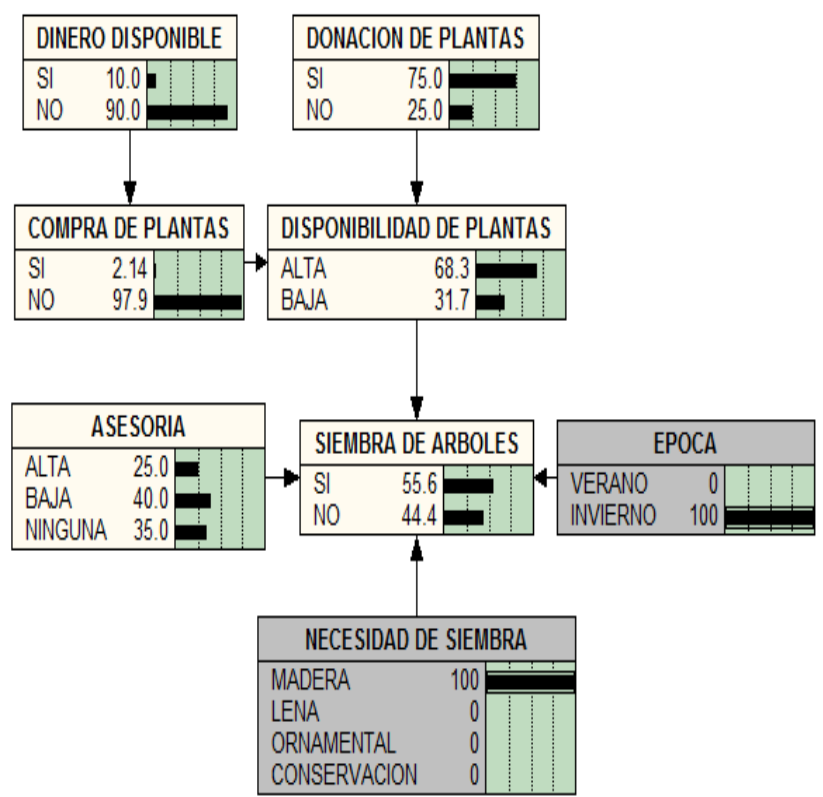

$100 \%$ y madera con $100 \%$ probabilidad (Fig. 14), la decisión de sembrar sería 19,9\% de probabilidad. Esto indica que si el agricultor dispone de plantas para la siembra en época de invierno, existe mayor probabilidad de sembrar árboles, ésto ayuda a la programación de donación de plantas a los productores ganaderos.

Simulando estados del $100 \%$ de probabilidad para las variables época invierno y necesidad de siembra para leña (Fig. 15), se encontró que la probabilidad de realizar la siembra es de $64,7 \%$. Por el contrario, si la época fuese verano con $100 \%$ y leña con $100 \%$ de probabilidades (Fig. 15), la decisión de sembrar pasaría a un 25,9\% de probabilidad. Esto sigue afirmando, que si el agricultor dispone de plantas para la siembra en época de invierno existe mayor probabilidad de sembrar árboles, porque la leña y la madera son las necesidades prioritarias de la finca, el consumo de leña es constante debido a la costumbre de cocinar y darse calor con la combustión de leña.

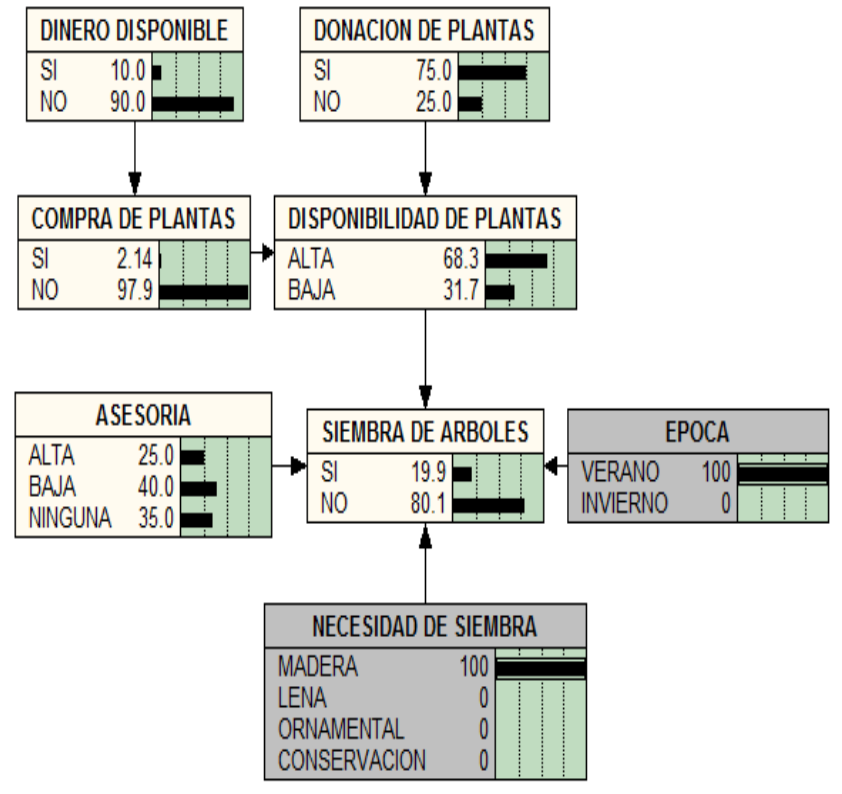

Figura 14. Simulación del evento siembra de árboles en diferentes escenarios 

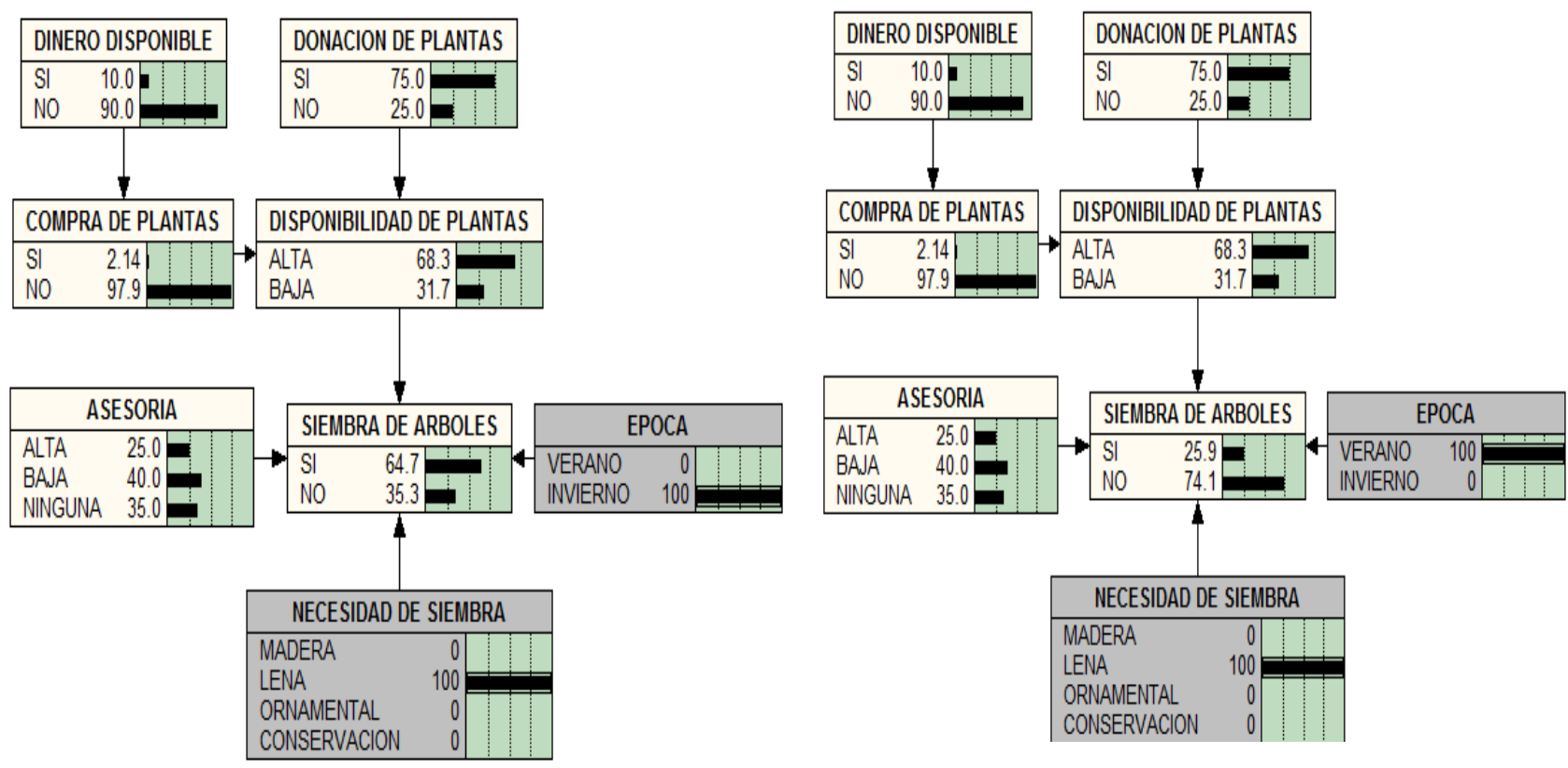

Figura 15. Simulación del evento siembra de árboles en diferentes escenarios

\section{CONCLUSIONES}

Los productores ganaderos de Cumbal y Guachucal, utilizan en su mayoría mano de obra familiar para todas las labores correspondiente al manejo de la cobertura arbórea.

El uso de leña en las fincas ganaderas, representa la actividad más significativa para la reducción de la cobertura arbórea.

Los ganaderos de Cumbal y Guachucal, no destinan dinero para el manejo de la cobertura arbórea, porque consideran que no es prioridad y no es su principal fuente de ingreso.

Los cuatro principales eventos, que intervienen en el manejo de la cobertura arbórea en Cumbal y Guachucal son la poda de árboles, control de maleza, aprovechamiento de árboles y siembra de árboles.

La poda, es la actividad que más se realiza para cubrir la necesidad de leña y postes. El aprovechamiento de árboles está influenciado por su no aceptación en la zona (Pinus patula, Eucaliptus globulus Labill, Cupresus lusitánica).

\section{BIBLIOGRAFÍA}

ALCALDÍA MUNICIPAL DE CUMBAL. 2006. Esquema de Ordenamiento territorial del municipio de Cumbal 2002 - 2012.

ALCALDÍA MUNICIPAL DE GUACHUCAL. 2006. Esquema de Ordenamiento Territorial municipio de Guachucal 2006 - 2015.

BARRIOS, C. 1998. Pastoreo regulado y bostas del ganado como herramientas forestales para la protección de arbolitos en potreros. Tesis Magister. Centro Agronómico Tropical de Investigación y Enseñanza. Turrialba, Costa Rica. 93p.

BOTINA, S. y TARAMUEL, A. 2009. Caracterización del conocimiento local del componente arbóreo en fincas ganaderas del municipio de Cumbal, Nariño. Tesis para optar el grado de 
Ingeniero Agroforestal, Universidad de Nariño. $26 \mathrm{p}$.

CAJAS, C., MARTÍNEZ, J. y NAVIA, J. 2009. Caracterización biofísica y socioeconómica en fincas ganaderas lecheras en el municipio de Cumbal, departamento de Nariño. Tesis para optar al grado de Ingeniero Agroforestal, Universidad de Nariño. 29 p.

CASASOLA, F. 2000. Productividad de los sistemas silvopastoriles tradicionales en Moropotente Estelí, Nicaragua. Tesis Magister. Centro Agronómico Tropical de Investigación y Enseñanza, Turrialba, Costa Rica. 95 p.

\section{CENTRO PARA LA INVESTIGACIÓN EN} SISTEMAS SOSTENIBLES DE PRODUCCIÓN AGROPECUARIA (CIPAV). 2001. Enfoques silvopastoriles integrados en el manejo de ecosistemas. Ganadería productiva sostenible.CIPAV. Cali, Colombia. 96 p.

CORAL, J., CORAL, B. D. y MUÑOZ, D. 2009. Caracterización del conocimiento local del componente arbóreo en fincas ganaderas de Pupiales, departamento de Nariño. Tesis para optar al grado de Ingeniero Agroforestal, Facultad de Ciencias Agrícolas, Universidad de Nariño. Pasto. 25 p.

DEFFONTAINES, J; THENAIL, C. y BAUDFY, J. 1995. Agricultural systems and landscape patterns: how can we build a relationship? Landscape and Urban Planning. 31:3 - 10.

DEPARTAMENTO ADMINISTRATIVO NACIONAL DE ESTADÍSTICAS (DANE). 2012. Boletín de prensa: Encuesta Nacional Agropecuaria. En: http:/ / www.dane.gov.co/; consulta: febrero, 2013.
FEDERACIÓN COLOMBIANA DE GANADEROS (FEDEGAN). 2012. La ganadería Colombiana y las cadenas láctea y cárnica. Plan Estratégico de la ganadería Colombiana, PEGA 2019. En: http://portal.fedegan.org.co/; consulta: febrero, 2013.

GLASER, B. y STRAUSS, A. 1967. The discovery of grounded theory; strategies for qualitative research. Chicago, Aldine Publishing Company. En: http://www.catedras.fsoc.uba. ar/ginfestad/biblio/1.10.\%20Glaser\%20y $\% 20$ Strauss.\%20El\%20metodo....pdf; consulta: diciembre, 2013.

GÓMEZ, R., LÓPEZ, M., HARVEY, C. y VILLANUEVA, C. 2004. Caracterización de las fincas ganaderas y sus relaciones con la cobertura arbóreas en Belén, Rivas, Nicaragua. Encuentro. 68:94 - 112 .

GRUPO EDITORIAL OCÉANO. 2000. Enciclopedia Práctica de la Agricultura y la Ganadería. Editorial Océano Centrum. Madrid, España. $312 \mathrm{p}$.

HOLMAN, F., MONTENEGRO, J., CHANA, C., OVIEDO, E. y BAÑOS, A 1992. Rentabilidad de los sistemas silvopastoriles con pequeños productores de leche en Costa Rica. Turrialba. 42:79 - 89 .

LASSO A. C., ZABULÓN D. E. y NAVIA E. J. F. 2009. Caracterización biofísica y socioeconómica en fincas ganaderas lecheras en el municipio de Cumbal, departamento de Nariño. Tesis para optar al grado de Ingeniero Agroforestal, Facultad de Ciencias Agrícolas, Universidad de Nariño. 25 p.

LEÓN G, J. A. 2006. Conocimiento local y razonamiento agroecológico para toma de 
decisiones en pasturas degradadas en El Peten Guatemala. Tesis Magister. Centro Agronómico Tropical de Investigación y Enseñanza. Turrialba, Costa. $100 \mathrm{p}$.

NORSYS, 1998. Netica 2.6 for Windows 95 and Windows NT 4.0. Norsys Software Corporación.

ROMERO, C. 1993. Teoría de la Decisión Multicriterio: Conceptos, técnicas y aplicaciones. Alianza Editorial S.A. Madrid.

TURCIOS, S. 2008. Evaluación del proceso de toma de decisiones para adopción de bancos de proteína de leucaena (Leucaena leucocephala) y su efecto como suplemento nutricional para vacas lactantes en sistemas doble propósito en el chal, Petén, Guatemala. Tesis Magister. Centro Agronómico Tropical de Investigación y Enseñanza. Turrialba, Costa. 125 p.

VILLANUEVA, C., IBRAHIM, M., HARVEY, C. A., SINCLAIR, F. L. y MUÑOZ, D. 2004. Decisiones claves que influyen sobre la cobertura arbórea en fincas ganaderas de Cañas, Costa Rica. Revista Agroforesteria en las Américas. 10:39 - 40 . 